\title{
Phase I clinical trial of human vascular endothelial growth factor receptor 1 peptide vaccines for patients with metastatic renal cell carcinoma
}

\author{
K Yoshimura ${ }^{1}, \mathrm{~T} \mathrm{Minami}^{1}$, M Nozawa ${ }^{1}$ and H Uemura*,1 \\ ${ }^{1}$ Department of Urology, Kinki University Faculty of Medicine, 377-2 Ohno-Higashi, Osaka-Sayama, Osaka 589-8511, Japan
}

Background: It is well known that renal cell carcinoma (RCC) represents one of the most immune-responsive cancers. Although the lack of defined antigens in RCC has hindered more specific vaccine development, research regarding vaccination therapy has been of special interest for the treatment of RCC for more than 30 years.

Methods: To evaluate the safety of the vascular endothelial growth factor receptor 1 (VEGFR1) peptide vaccination and its clinical outcomes, data from 18 metastatic RCC (mRCC) patients treated with VEGFR1 vaccine were collected. Toxicity assessments were performed. Clinical outcomes included assessment using CT scanning, magnetic resonance imaging or X-ray examination in accordance with the WHO Response Evaluation Criteria in Solid Tumors.

Results: No patient showed any toxicities of grade 3 or greater. Of the 18 patients, 2 patients showed a partial response during treatment. Stable disease for more than 5 months was observed in eight patients with a median duration of 16.5 months (4-32 months). At the time of the analysis in this study, six patients were alive with a median follow-up of 30 months (26-36 months).

Conclusion: These results suggest that VEGFR1 peptide vaccine is safe and is recommended for further trials for patients with mRCC.

Renal cell carcinoma (RCC) is the most common type of kidney tumours in adults, responsible for $\sim 80 \%$ of cases. It is well known that where the tumour is confined to the renal parenchyma, the prognosis is relatively good and 5 -year survival rate is $70-80 \%$. In such cases, initial treatment is most commonly a radical or partial nephrectomy and remains the mainstay of curative treatment (Rini et al, 2008).

In the era of molecular targeted agents, new immunotherapy trials such as vaccination with tumour lysate, loaded autologous dendritic cells have shown some benefits, although the complicated procedures of dendritic cell vaccine and its low response rates have hampered the wide prevalence of dendritic cell treatment. So far, a large number of tumour-associated antigens and their peptides recognised by MHC class I-restricted cytotoxic $\mathrm{T}$ lymphocytes
(CTLs) have been identified in various malignancies (Kawakami et al, 1994a,b; Fisk et al, 1995; Robbins et al, 1996; Correale et al, 1997) and used in clinical trials (Finn and Lotze, 2001; Slingluff et al, 2001; Ramanathan et al, 2005; von Mehren, 2005). In search for RCC-associated antigen peptides available to induce CTLs, we have also identified three carbonic anhydrase 9 (CA9) antigenderived peptides and have shown their ability to induce human leukocyte antigen (HLA)-A24-restricted, CA9-specific CTLs (Shimizu et al, 2003; Uemura et al, 2006).

Similarly, peptide vaccine therapy has been attempted since the identification of epitope peptides. However, because of their minimal clinical responses, several mechanisms of immune evasion of tumours have been implicated as issues to improve cancer immunotherapy. For instance, the antitumor effect of CTLs

*Correspondence: Dr H Uemura; E-mail: huemura@med.kindai.ac.jp

Received 28 November 2012; revised 5 February 2013; accepted 12 February 2013;

published online 7 March 201

(c) 2013 Cancer Research UK. All rights reserved 0007-0920/13

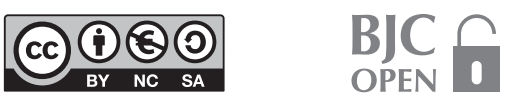


induced by peptide vaccine was suspected to be inhibited because of tumour cell heterogeneity, and also the downregulation or loss of HLA or antigen proteins (Khong and Restifo, 2002; Ryschich et al, 2005). The vascular endothelial growth factor receptor 1 (VEGFR1) peptide is an immunogenic peptide derived from VEGFR1 restricted with HLA-A2 and A24, which are common HLA-A allele in Japanese population. VEGFR1 is an important factor in tumour angiogenesis (Shibuya, 1995; Dvorak, 2002; Li et al, 2002) and in the growth of RCC. In this study, a phase I clinical trial of VEGFR1 peptide vaccines was carried out in patients with metastatic RCC (mRCC) to assess toxicity, induction of immune responses and clinical usefulness.

\section{PATIENTS AND METHODS}

Patient eligibility. Patients with mRCC and pathologically confirmed clear cell carcinoma were candidates for this study. All patients had progressive disease after standard cytokine therapy, such as IL- 2 and/or IFN- $\alpha$ and molecular targeted therapy (sorafenib and sunitinib). Patient eligibility included the following: HLA-A2 and/or A24 positivity; age 20 to 80 years; an Eastern Cooperative Oncology Group performance status of 0 or 1; granulocyte count $\geqslant 3000$ per $\mathrm{mm}^{3}$; haemoglobin $\geqslant 10 \mathrm{~g} \mathrm{dl}^{-1}$; platelets $\geqslant 100000$ per $\mathrm{mm}^{3}$; bilirubin and creatinine equal to or less than the institutional normal limits; life expectancy $\geqslant 12$ weeks; measurable or evaluable disease; no immunotherapy, chemotherapy or radiotherapy within 4 weeks (washout for 4 weeks); and negative serological tests for hepatitis B, hepatitis C and HIV. Patients with serious illness or an active secondary malignancy were excluded. Other exclusion criteria also included existence of immunosuppressive or autoimmune disease, or receipt of immunosuppressive agents (e.g., steroids). All patients were informed of the investigational nature of the study, and signed informed consent in accordance with the institutional guideline was obtained. This study was approved by the Kinki University institutional review board, and all subjects provided written informed consent before commencing study-related procedures. Each patient underwent a complete pretreatment clinical evaluation, including a clinical history, physical examinations with assessment of performance status, laboratory studies, and measurements of radiographic studies.

Patient demographics. From May 2007 to November 2009, 18 patients with cytokine-refractory and tyrosine kinase inhibitor (TKI) failure mRCC were enroled at the Kinki University Hospital. All patients previously underwent radical nephrectomy of the primary tumour and had clear cell carcinoma. The characteristics of the patients are summarised in Table 1. The median age of the patients was 66 years (range, 44-78 years). All patients had a performance status of 0 and distant metastases at the time of enrolment as shown in Table 1.

Peptides. The good manufacturing practice (GMP)-graded VEGFR1-770 peptide restricted with HLA-A0201 (TLFWLLLTL) and the GMP-graded VEGFR1-1084 peptide restricted with HLAA2402 (SYGVLLWEI) were synthesised by the American Peptide Company (Sunnyvale, CA, USA) according to a standard solidphase synthesis method and were purified by reversed-phase highperformance liquid chromatography. Human leukocyte antigenA0201-restricted CMV peptide (NLVPMVATV) and HIV peptide (ILKEPVHGV), and HLA-A2402-restricted CMV peptide (QYDPVAALF) and HIV peptide (RYLRDQQLL) were used for CTL response measurements.

Study design and treatment protocol. This study was a nonrandomised, open-label, phase I clinical trial with dose escalation of the VEGFR1-770/1084 peptide for patients with mRCC. Two VEGFR1 peptide vaccines were derived from VEFGR1 restricted with HLA-A0201 or A2402. In this study, the patients were administered either HLA-A0201-restricted peptide or A2402restricted peptide. The primary endpoint of this trial was the safety of vaccination. The secondary endpoints were immunological responses, clinical outcomes, and the determination of the

Table 1. Patient demographics of the peptide vaccination

\begin{tabular}{|c|c|c|c|c|c|c|c|}
\hline $\mathrm{Pt}$ & Age & Sex & Clinical stage at $\mathbf{N x}$ & Histological type & Metastases & Previous treatment & PS \\
\hline A2-1 & 66 & $\mathrm{~F}$ & pT3NOMO & Clear cell carcinoma & Lung/LN & $\mathrm{N} x / \mathrm{IFN}$ & 0 \\
\hline A2-2 & 61 & $M$ & pT1bN1M0 & Clear cell carcinoma & Lung/LN & $\mathrm{Nx} / \mathrm{IFN}$ & 0 \\
\hline A2-3 & 65 & $\mathrm{M}$ & pT2N0M1 & Clear cell carcinoma & Pancreas & $\mathrm{Nx} / \mathrm{IL}-2 / \mathrm{IFN}$ & 0 \\
\hline A2-4 & 44 & $M$ & pT1bN0M0 & Clear cell carcinoma & Lung/LN & $\mathrm{Nx} / \mathrm{IFN} / \mathrm{So}$ & 0 \\
\hline$A 2-5$ & 77 & $\mathrm{M}$ & pT3NOMO & Clear cell carcinoma & LN/liver & Nx/IL-2/IFN/So & 0 \\
\hline A2-6 & 53 & $\mathrm{~F}$ & pT2N0M1 & Clear cell carcinoma & Lung & $\mathrm{Nx} / \mathrm{IL}-2 / \mathrm{IFN} / \mathrm{So}$ & 0 \\
\hline A2-7 & 66 & $\mathrm{M}$ & pT3N1M1 & Clear cell carcinoma & Lung/bone & $\mathrm{N} x / \mathrm{IL}-2 / \mathrm{IFN} / \mathrm{So}$ & 0 \\
\hline A2-8 & 69 & $\mathrm{M}$ & pT2N0M1 & Clear cell carcinoma & Lung & $\mathrm{N} x / \mathrm{IL}-2 / \mathrm{IFN} / \mathrm{Su}$ & 0 \\
\hline A2-9 & 73 & $\mathrm{M}$ & pT3N2M1 & Clear cell carcinoma & Lung/pancreas & $\mathrm{N} x / \mathrm{IFN} / \mathrm{So} / \mathrm{Su}$ & 0 \\
\hline A24-1 & 49 & $\mathrm{M}$ & pT1bNOM0 & Clear cell carcinoma & Lung/LN & Nx/IFN/So & 0 \\
\hline A24-2 & 74 & $\mathrm{M}$ & pT3N0M1 & Clear cell carcinoma & Lung/LN & $\mathrm{Nx} / \mathrm{IL}-2 / \mathrm{IFN}$ & 0 \\
\hline A24-3 & 75 & $\mathrm{M}$ & pT3N2M0 & Clear cell carcinoma & Lung/LN & $\mathrm{N} \times /$ IL-2/IFN & 0 \\
\hline A24-4 & 61 & $\mathrm{M}$ & pT3N0M1 & Clear cell carcinoma & Adrenal/brain & $\mathrm{N} \times / \mathrm{IL}-2 / \mathrm{IFN}$ & 0 \\
\hline A24-5 & 49 & $\mathrm{M}$ & pT3N2M0 & Clear cell carcinoma & Lung/LN & Nx/IL-2/IFN/So & 0 \\
\hline A24-6 & 69 & $\mathrm{M}$ & pT3N0M1 & Clear cell carcinoma & Lung/liver/pancreas & $\mathrm{N} x / \mathrm{IL}-2 / \mathrm{IFN} / \mathrm{So}$ & 0 \\
\hline A24-7 & 78 & $\mathrm{~F}$ & pT3N2M0 & Clear cell carcinoma & Lung/bone & $\mathrm{N} x / \mathrm{IL}-2 / \mathrm{IFN} / \mathrm{Su}$ & 0 \\
\hline A24-8 & 61 & M & pT3N2M1 & Clear cell carcinoma & Bone & Nx/IL-2/IFN/So & 0 \\
\hline A24-9 & 69 & M & pT1bN0M1 & Clear cell carcinoma & Lung/LN & $\mathrm{Nx} / \mathrm{IFN} / \mathrm{So} / \mathrm{Su}$ & 0 \\
\hline
\end{tabular}

Abbreviation: $F=$ female; IFN= interferon- $\alpha$; IL-2=interluekin-2; $L N=$ lymph node; $M=$ male; $N x=$ nephrectomy; PS = performance status; $\mathrm{Pt}=$ patient; So = sorafenib; Su=sunitinib. 
optimal dose of peptide. The dose was escalated as $0.5,1.0$, and $3.0 \mathrm{mg}$ per body of the vaccinated peptide. The washout period of the previous treatment was 4 weeks. The VEGFR1 peptide vaccine was emulsified with incomplete Freund's adjuvant (Montanide ISA-51VG; Seppic, Paris, France) and subcutaneously administered into the site of the upper arm on days $1,8,15$, and 22 in a 28 -day treatment cycle. After one course of treatment, the safety of the peptide was evaluated (Figure 1). If the patient was evaluated favourably, the administration of VEGFR1 vaccine was continued every 2 weeks until death, intolerance, marked disease progression, major violations, or patients' withdrawal of consent.

Clinical assessment. All patients were followed up until death due to disease, intolerance, or self-withdrawal. Toxicity assessments were done at least every 2 weeks using the National Cancer Institute Common Terminology Criteria for Adverse Events v3.0. Clinical and laboratory assessments were checked at each visit. Clinical outcomes included assessment using CT scanning, magnetic resonance imaging, bone scintigram, or X-ray examination in accordance with the WHO Response Evaluation Criteria in Solid Tumors (RECIST). Radiological evaluation was performed at 2 to 4 weeks after one course of vaccination and every 3 months thereafter. Overall survival (OS) was estimated from the date of the initial vaccination to the date of death using the Kaplan-Meier method.

Immunological monitoring. To measure CTL responses against peptide, an enzyme-linked immunospot (ELISPOT) assay was performed. The detail method of our ELISPOT assay was described elsewhere (Miyazawa et al, 2010; Okuno et al, 2011). Peripheral blood mononuclear cells (PBMC) were obtained from patients at pre- and post vaccine treatment at the end of each course, and then frozen and stored in liquid nitrogen until their use. The frozen PBMCs derived from the same patient were thawed at the same time, cultured with respective peptide and IL-2 (Novartis, Emeryville, CA, USA), and were collected after 2 weeks. Following $\mathrm{CD} 4+$ cell depletion, IFN- $\gamma$ ELISPOT assay was performed with peptide-pulsed or HIV-pulsed (as the control) HLA-A0201positive T2 cells (ATCC, Rockville, MD, USA) and HLA-A2402positive TISI cells (IHWG Cell and Gene Bank, Seattle, WA, USA) using the Human IFN- $\gamma$ ELISpot PLUS kit (MabTech, Cincinnati, OH, USA) and the MultiScreen-IP 96-plate (Millipore, Bedford, MA, USA). The plates were analysed by the automated ELISPOT reader, ImmunoSPOT S4 (Cellular Technology Ltd, Cleveland, $\mathrm{OH}, \mathrm{USA}$ ). All ELISPOT assays were performed in triplicate. The number of peptide-specific spots was calculated by subtracting the spot number in the wells of the control cells from that in the well with the peptide-pulsed T2 or TISI cells. The peptide-specific $\mathrm{T}$-cell response was classified into four grades $(-,+,++$,

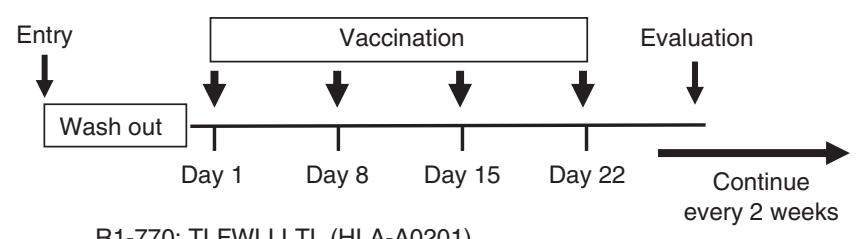

R1-1084: SYGVLLWEI (HLA-A2402)

Dose-escalation protocol

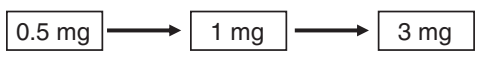

Figure1. Treatment protocol. VEGFR1 vaccine was administered subcutaneously on days $1,8,15$, and 22 in a 28-day treatment cycle. After evaluation, vaccination was continued every 2 weeks. The amino acid sequences of the two VEGFR1 vaccine are shown. The dose administered was designed in a dose-escalation manner. and +++$)$ according to the algorithm flowchart described in our previous report (Kono et al, 2012). Sensitivity of our ELISPOT assay was estimated as an approximately average level among participating laboratories in the ELISPOT panel of the Cancer Immunotherapy Consortium in 2009 and 2011. Peptide-specific CTL precursors in PBMCs were detected using IFN- $\gamma$ release assay as previously described (Hida et al, 2002; Maeda et al, 2002; Suzuki et al, 2002). The data were considered positive (specific CTL induction) when the level of IFN- $\gamma$ production in response to each corresponding peptide was significantly higher $(P<0.05)$ than that in response to HIV control peptide. All experiments were performed in four different wells and in duplicates.

\section{RESULTS}

Safety. The overall toxicity of the 18 patients is summarised in Table 2. No patient showed any toxicities of grade 3 or greater. Of the 18 patients, 10 patients developed grade 1 or 2 local skin reaction at the injection sites with induration, redness, and swelling. Four patients experienced grade 1 fever but no medication was required. Grade 1 fatigue was observed in one patient with HLA-A2-restricted peptide vaccine. Grade 1 headache was noted in one patient with HLA-A2-restricted peptide vaccine and three patients complained of rashes, which were resolved without any medications. In this study, no case revealed any vascular adverse events, such as hypertension, bleeding, and thromboembolism, and no hepatic or renal toxicities were also found during vaccination. In addition, no dose-limiting toxicities were observed in this trial.

Cellular immune responses. The positive CTL responses after the first course of vaccination were found in five of the six patients (83\%) receiving $0.5 \mathrm{mg}$ per body vaccination, five of the six patients (83\%) receiving $1 \mathrm{mg}$ per body, and three of the six patients (50\%) receiving $3 \mathrm{mg}$ per body, respectively (Table 3 ). Two patients were not evaluated on CTL induction. Overall, of the 18 patients, 15 patients $(83 \%)$ who received at least one course of vaccination revealed positive CTL responses. Peptide-specific delayed-type hypersensitivity reactions were observed in six patients. The representative data from the IFN- $\gamma$ ELISPOT assay and CTL responses in the patient who received peptide vaccine derived from VEGFR1 restricted with HLA-A2 before and after the treatment are shown in Figure 2.

Clinical outcomes. Of the 18 patients, 2 patients showed a partial response (PR) during treatment (Table 3 ). One of the two PR

\begin{tabular}{|c|c|c|c|c|c|}
\hline & \multicolumn{5}{|c|}{ Grade } \\
\hline Toxicity & 1 & 2 & 3 & 4 & Total \\
\hline Local reaction ${ }^{\mathrm{a}}$ (A2/A24) & $4(2 / 2)$ & $5(0 / 5)$ & 0 & 0 & $9(2 / 7)$ \\
\hline Induration (A2/A24) & $3(1 / 2)$ & $5(0 / 5)$ & 0 & 0 & $8(1 / 7)$ \\
\hline Redness (A2/A24) & $2(1 / 1)$ & 0 & 0 & 0 & $2(1 / 1)$ \\
\hline Swelling (A2/A24) & $1(0 / 1)$ & 0 & 0 & 0 & $1(0 / 1)$ \\
\hline Fever (A2/A24) & $4(2 / 2)$ & 0 & 0 & 0 & $4(2 / 2)$ \\
\hline Fatigue (A2/A24) & $1(1 / 0)$ & 0 & 0 & 0 & $1(1 / 0)$ \\
\hline Headache (A2/A24) & $1(1 / 0)$ & 0 & 0 & 0 & $1(1 / 0)$ \\
\hline Rash (A2/A24) & $3(2 / 1)$ & 0 & 0 & 0 & $3(2 / 1)$ \\
\hline
\end{tabular}


Table 3. Clinical and immunological outcomes of the peptide vaccination

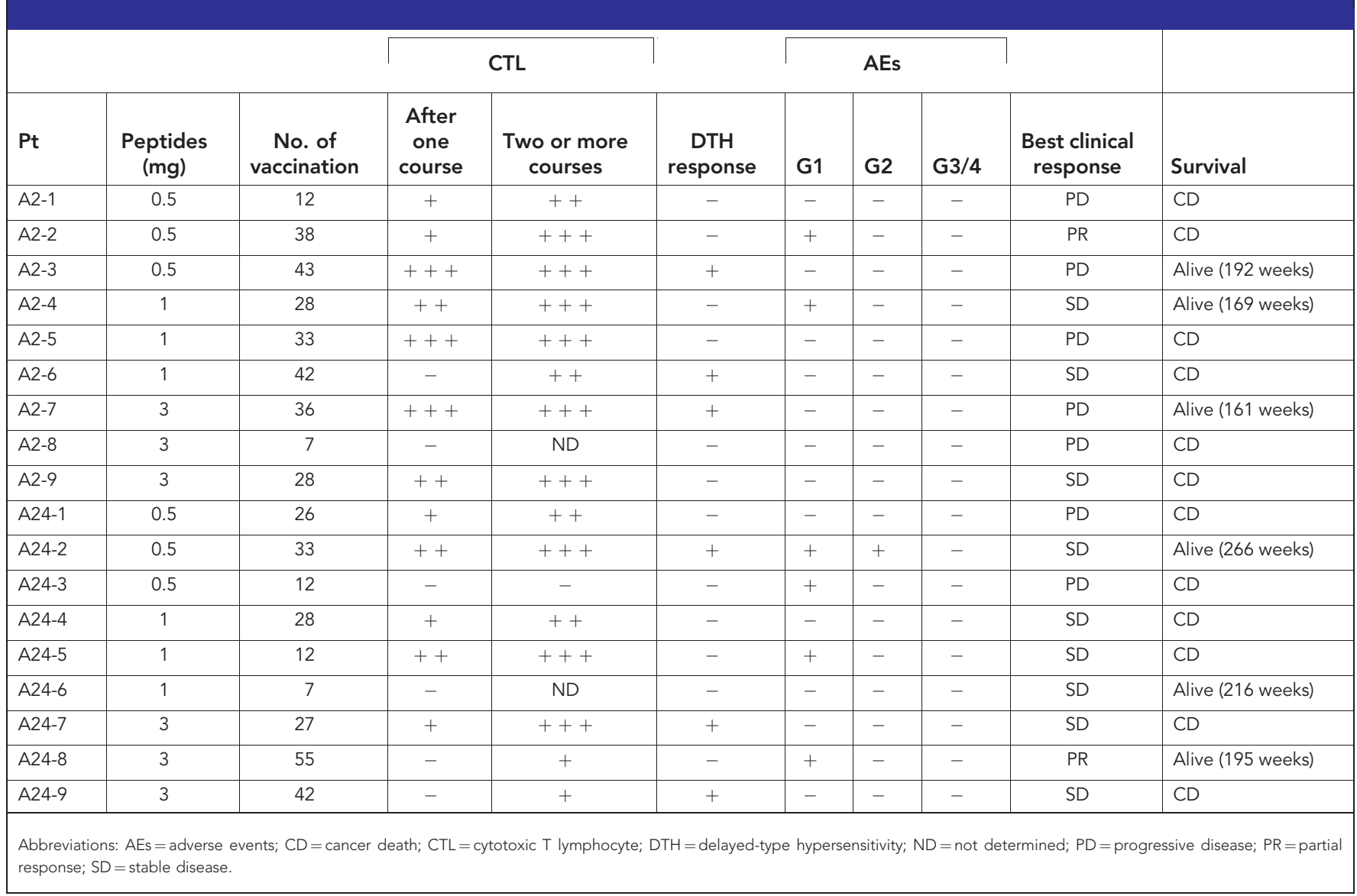

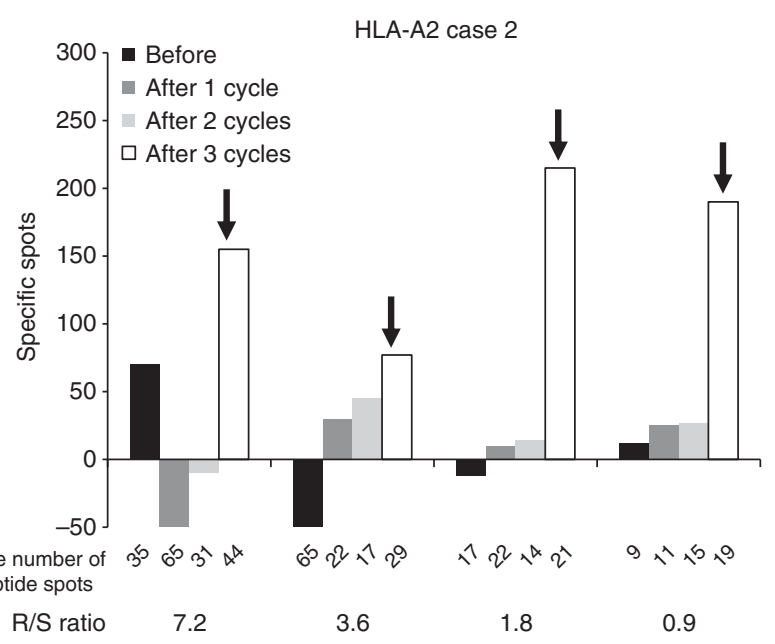

Figure 2. Changes of CTL response after vaccination. Significant induction of CTL was observed by VEGFR1 peptide vaccine.

patients, who had multiple metastases in lung and regional lymph nodes, showed shrinking of pulmonary lesions and maintained PR for 5 months (Figure 3A). However, this patient developed pancreas metastasis and died of cancer 18 months after initiation of vaccine treatment. The rest of the two had multiple bone metastases resistant to IL-2/IFN/sorafenib treatment. This patient achieved PR with shrinking of the bone metastatic lesions, which were evaluated with both CT scan and bone scintigram, and, at present, is stable continuing vaccine treatment for 36 months
(Figure 3B). Stable disease for more than 5 months was observed in eight patients with a median duration of 16.5 months (4-32 months). The remaining eight patients had no clinical responses. At the time of the analysis in this study, 12 patients died due to RCC and 6 patients were alive with a median follow-up of 30 months (26-36 months). Median OS of the patients with the HLAA2-restricted peptide was 85 weeks and that of those with HLAA24-restricted peptide was 45 weeks. The entire OS curve is shown in Figure 4, indicating a median OS of 70 weeks.

\section{DISCUSSION}

Renal cell carcinoma is the most common type of kidney tumours in adults, which accounts for $2-3 \%$ of all adult cancers, and $\sim 20$ $30 \%$ of patients present with metastatic disease. Although a radical or partial nephrectomy is the primary curative therapy for patients with localised RCC, the prognosis for patients with advanced mRCC is poor, with a 5 -year survival rate of $<10 \%$ (Schrader et al, 2006). As RCC is one of the most immunoresponsive cancers in humans, immunotherapy remains a basis of promising treatment strategies. Until recently, the standard therapy for $\mathrm{mRCC}$ has been cytokine-based immunotherapy with IL- 2 and/or IFN- $\alpha$ with only few durable complete remissions.

Recently, molecular targeted agents, such as TKIs and mTOR inhibitors, have been introduced to the treatment of mRCC, which have improved the outlook for $\mathrm{mRCC}$ in clinical responses, especially in progression-free survival. However, they have not yet demonstrated improved OS remarkably. Under these circumstances, several clinical trials of peptide-based vaccine treatment 
A

HLA-A2, case 2: 61 years old, male, IFN failure, lung metastases

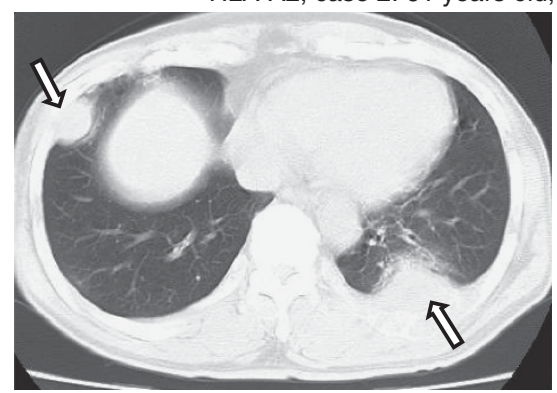

Before vaccination

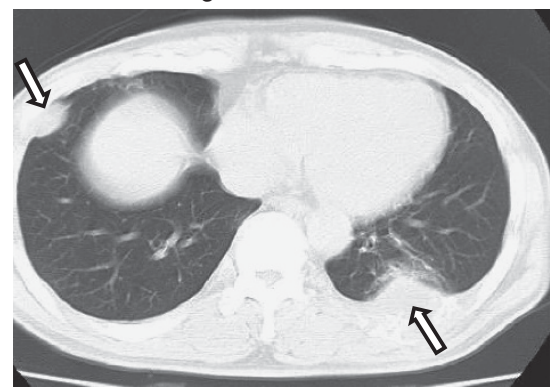

3 Months after vaccination

B

HLA-A24, case 8: 61 years old male, IL2/IFN/sorafenib failure, multiple bone metastases

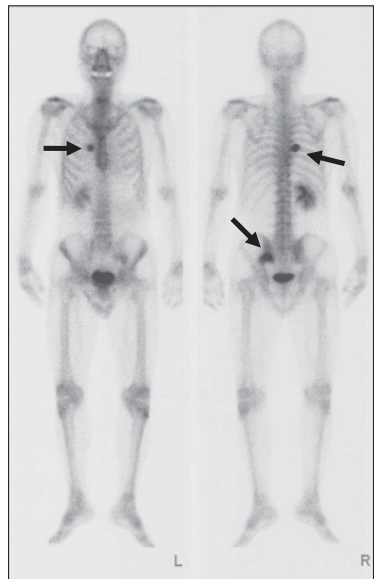

Before vaccination



After third course

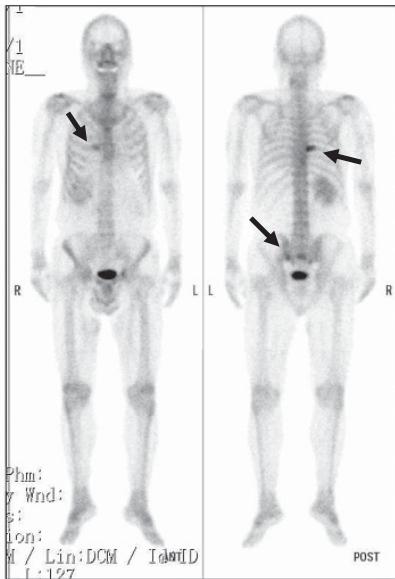

36 Months after vaccinations

Figure 3. Instance of VEGRF1 vaccine responder. (A) The patient had lung metastases resistant to IFN treatment. Shrinking of lung metastases was noted. (B) The patient had multiple bone metastases resistant to IL-2/IFN/sorafenib treatment. He achieved PR with shrinking of the bone metastatic lesions, and, at present, is stable continuing vaccine treatment.

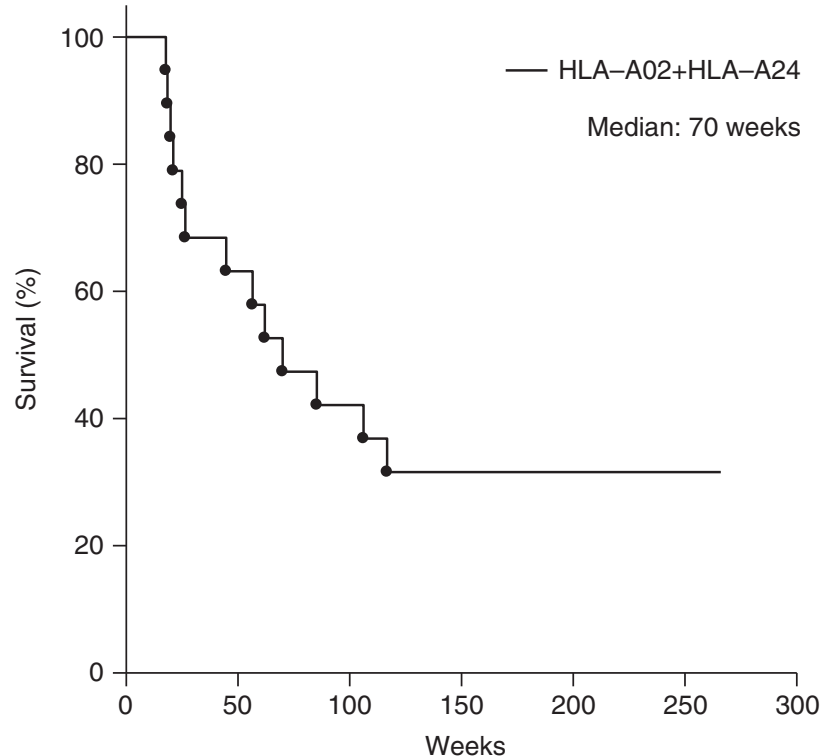

Figure 4. The entire overall survival curve is indicated with a median OS of 70 weeks.

have been done in recent years. The RCC vaccines are explored in metastatic and adjuvant settings. To date, they are clinically effective only in a minority of patients and, generally, are still considered experimental. Much attention has been given to CA9 that is overexpressed in $\sim 90 \%$ of all RCC types.

In addition to CA9-derived peptides, several new RCCassociated antigens and derived MHC class I-restricted ligands were recently introduced in some clinical trials (Iiyama et al, 2007; Suekane et al, 2007; Patel et al, 2008). Recently, Walter et al (2012) reported the outcomes of phase I/II clinical trials using multiple tumour-associated peptides (TUMAPs) called IMA901. They treated a total of 96 HLA-A02-positive patients with mRCC with IMA901 in two consecutive studies. In the phase I study, they showed that the T-cell responses of the patients to multiple TUMAPs were associated with better disease control. The randomised phase II trial demonstrated that a single dose of cyclophosphamide administration before IMA901 immunotherapy reduced the number of T-regulatory cells and confirmed that immune responses to multiple TUMAPs were associated with longer OS. A randomised phase III study to determine the clinical benefit of treatment with IMA901 is now ongoing (NCT 01265901). IMA901 multipeptide vaccine is considered one of the most available peptide vaccines in practical clinic, such as sipuleucel $\mathrm{T}$, in the near future.

Vascular endothelial cells have crucial roles in the growth and progression of tumours and stably express HLA molecules. Vascular endothelial growth factor receptor 1, which is a functional molecule associated with neovascularisation, is highly expressed in newly induced tumour blood vessels, but not in normal vessels. It is an important factor in tumour angiogenesis (Shibuya, 1995; Dvorak, 2002; Li et al, 2002) and in the growth of RCC. The VEGFR1 peptide we used in this study is an immunogenic peptide 
derived from VEGFR1 restricted with HLA-A2 and A24, which are common HLA-A allele in the Japanese population. In this study, we administered peptide vaccines in a dose-escalation manner $(0.5$, $1.0,3.0 \mathrm{mg}$ per body, respectively). The primary endpoint was to evaluate the safety and toxicity of VEGFR1 peptide vaccination. All patients had only minor adverse events and, therefore, this vaccine treatment is considered well tolerated and acceptable for mRCC patients. One of the secondary objectives of this investigation was to evaluate vaccine-induced specific immune reactions. As a result, the specific CTL responses against the vaccinated peptide were observed in 15 (83\%) of the 18 patients, clearly demonstrating that CTL against VEGFR1 could be induced by a vaccination of the VEGFR1 peptide, although no obvious correlations of CTL responses and clinical outcomes were found in this study. A similar result is shown in patients with advanced gastric cancer (Masuzawa et al, 2012). Further investigations are required to confirm this problem, because a relatively small number of patients $(n=18)$ was enroled in this phase I study. The other secondary endpoint was the determination of the optimal dose of peptide. The specific CTL responses against the peptide were observed equally in $0.5,1$, and $3.0 \mathrm{mg}$ peptide group, respectively, and no dose-limiting toxicities were found in this study. On the basis of these results, $3 \mathrm{mg}$ of peptide vaccine may be safe and available in future clinical trials. Clinically, two patients showed a clinical response during treatment. One of the patients who has PR with multiple bone metastases, who was evaluated with both CT and bone scan, was considered to have PR according to RECIST v1.0. When RESIST v1.1 was used for evaluation, this patient was not considered to have PR, because apparent reduction of soft tissue metastases in bone is needed not only for bone scan but also for CT scan. However, the patient is stable and is continuing the vaccine treatment. Therefore, we evaluated the patient who achieved PR as shown in Figure 3B. Stable disease for more than 5 months was observed in eight patients, with a median duration of 16.5 months (4-32 months). The remaining eight patients had no clinical responses. As a result, 12 patients died due to RCC and 6 patients remained alive, with a median follow-up of 30 months (26-36 months) so far.

In conclusion, treatment of mRCC patients with VEGFR1 peptide vaccines was well tolerated, and induction of antigenspecific immunity was observed in two-thirds of the patients. In the era of molecular targeted therapy, the observed clinical outcomes of the peptide vaccine therapy in this study are encouraging. Further well-designed clinical trials, including optimally selected patients, will be required in the use of peptide vaccines for mRCC.

\section{ACKNOWLEDGEMENTS}

We thank Professor Yusuke Nakamura, Dr Takuya Tsunoda, Dr Koji Yoshida, Laboratory of Molecular Medicine, Human Genome Center, Institute of Medical Science, University of Tokyo, for their excellent advice and cooperation and for providing all the peptides.

\section{CONFLICT OF INTEREST}

The authors declare no conflict of interest.

\section{REFERENCES}

Correale P, Walmsley K, Nieroda C, Zaremba S, Zhu M, Schlom J, Tsang KY (1997) In vitro generation of human cytotoxic T lymphocytes specific for peptides derived from prostate-specific antigen. J Natl Cancer Inst 89: 293-300.
Dvorak HF (2002) Vascular permeability factor/vascular endothelial growth factor: a critical cytokine in tumor angiogenesis and a potential target for diagnosis and therapy. J Clin Oncol 20: 4368-4380.

Finn OJ, Lotze MT (2001) A decade in the life of tumor immunology. Clin Cancer Res 7: 759-760.

Fisk B, Blevins TL, Wharton J, Ioannides CG (1995) Identification of an immunodominant peptide of HER2/neu proto-oncogene recognized by ovarian tumor-specific cytotoxic T lymphocytes line. J Exp Med 181: 2109-2117.

Hida N, Maeda Y, Katagiri K, Takasu H, Harada M, Itoh K (2002) A simple culture protocol to detect peptide-specific otoxic T lymphocyte precursors in circulation. Cancer Immunol Immunother 51: 219-228.

Iiyama T, Udaka K, Takeda S, Takeuchi T, Adachi T, Ohtsuki Y, Tsuboi A, Nakatsuka S, Elisseeva OA, Oji Y, Kawakami M, Nakajima H, Nishida S, Shirakata T, Oka Y, Shuin T, Sugiyama H (2007) WT1 (Wilms' tumor 1) peptide immunotherapy for renal cell carcinoma. Microbiol Immunol 51: 519-530.

Kawakami Y, Eliyahu S, Delgado CH, Robbins PF, Sakaguchi K, Appella E, Yannelli JR, Adema GJ, Miki T, Rosenberg SA (1994) Identification of a human melanoma antigen recognized by tumor-infiltrating lymphocytes associated with in vitro tumor rejection. Proc Natl Acad Sci USA 91: 6458-6462.

Kawakami Y, Eliyahu S, Sakaguchi K, Robbins PF, Rivoltini L, Yannelli JR, Appella E, Rosenberg SA (1994) Identification of the immunodominant peptides of the MART-1 human melanoma antigen recognized by the majority of HLA-A2 restricted tumor infiltrating lymphocytes. J Exp Med 180: 347-352.

Khong HT, Restifo NP (2002) Natural selection of tumor variants in the generation of 'tumor escape' phenotypes. Nat lmmunol 3: 999-1005.

Kono K, Iimura H, Akutsu Y, Tanaka H, Hayashi N, Uchikado Y, Noguchi T, Fujii H, Okinaka K, Fukushima R, Matsubara H, Ohira M, Baba H, Natsugoe S, Kitano S, Takeda K, Yoshida K, Tsunoda T, Nakamura Y (2012) Multicenter, phase II clinical trial of cancer vaccination for advanced esophageal cancer with three-peptides derived from novel cancer-testis antigens. $J$ Transl Med 10: 141.

Li Y, Wang MN, Li H, King KD, Bassi R, Sun H, Santiago A, Hooper AT, Bohlen P, Hicklin DJ (2002) Active immunization against the vascular endothelial growth factor receptor flk 1 inhibits tumor angiogenesis and metastasis. J Exp Med 195: 1575-1584.

Maeda Y, Ito M, Harashima N, Nakatsura T, Hida N, Imai N, Sato Y, Shichijo S, Itoh K (2002) Cleavage and polyadenylation specificity factor (CPSF)-derived peptides can induce HLA-A2-restricted and tumor specific CTLs in the majority of gastrointestinal cancer patients. Int $J$ Cancer 99: 409-417.

Masuzawa T, Fujiwara Y, Okada K, Nakamura A, Takiguchi S, Nakajima K, Miyata H, Yamasaki M, Kurokawa Y, Osawa R, Takeda K, Yoshida K, Tsunoda T, Nakamura Y, Mori M, Doki Y (2012) Phase I/II study of S-1 plus cisplatin combined with peptide vaccines for human vascular endothelial growth factor receptor 1 and 2 in patients with advanced gastric cancer. Int J Oncol; e-pub ahead of print 25 July 2012; doi:10.3892/ijo.2012.1573.

Miyazawa M, Ohsawa R, Tsunoda T, Hirano S, Kawai M, Tani M, Nakanura Y, Yamaue H (2010) Phase I clinical trial using peptide vaccine for human vascular endothelial growth factor receptor 2 in combination with gemcitabine for patients with advanced pancreatic cancer. Cancer Sci 101: 433-439.

Okuno K, Sugiura F, Hida JI, Tokoro T, Ishimaru E, Sukegawa Y, Ueda K (2011) Phase I clinical trial of a novel peptide vacccine in combination with UFT/LV for metastatic colorectal cancer. Exp Ther Med 2: 73-79.

Patel PM, Sim S, O'Donnell DO, Protheroe A, Beirne D, Stanley A, Tourani JM, Khayat D, Hancock B, Vasey A, Dalgleish A, Johnston C, Banks RE, Selby PJ (2008) An evaluation of a preparation of Mycobacterium vaccae (SRL172) as an immunotherapeutic agent in renal cancer. Eur J Cancer 44: 216-223.

Ramanathan RK, Lee KM, Mckolanis J, Hitbold E, Schraut W, Moser AJ, Warnick E, Whiteside T, Osborne J, Kim H, Day R, Troetsvhel M, Finn OF (2005) Phase I study of a MUClvaccine composed of different doses of MUC1 peptide with SB-AS2 adjuvant in resected and locally advanced pancreatic cancer. Cancer Immunol Immunother 54: 254-264.

Rini BI, Rathmell WK, Godley P (2008) Renal cell carcinoma. Curr Opin Oncol 20: 300-306.

Robbins PF, El-Gamil M, Li YF, Kawakami Y, Loflus D, Appella E, Rosenberg SA (1996) A mutated $\beta$-catenin gene encodes a melanoma-specific antigen recognized by tumor infiltrating lymphocytes. J Exp Med 183: 1185-1192. 
Ryschich E, Nötzel T, Hinz U, Autschbach F, Ferguson J, Simon I, Weitz J, Fröhlich B, Klar E, Büchler MW, Schmidt J (2005) Control of T cellmediated immune response by HLA class I in human pancreatic carcinoma. Clin Cancer Res 11: 498-504.

Schrader AJ, Varga Z, Hegele A, Ofoertner S, Olbert P, Hofmann R (2006) Second-line strategies for metastatic renal cell carcinoma: classics and novel approaches. J Cancer Res Clin Oncol 132: 137-149.

Shibuya M (1995) Role of VEGF-flt receptor system in normal and tumor angiogenesis. Adv Cancer Res 67: 281-316.

Shimizu K, Uemura H, Yoshikawa M, Yoshida K, Hirao Y, Iwashima K, Saga S, Yoshikawa K (2003) Induction of antigen specific cellular immunity by vaccination with peptides from MN/CA IX in renal cell carcinoma. Oncol Rep 10: 1307-1311.

Slingluff Jr. CL, Yamshchikov G, Neese P, Galavotti H, Eastham S, Enqelhard VH, Kittlesen D, Deacon D, Hibbitts S, Grosh WW, Petroni G, Cohen R, Wiernasz C, Patterson JW, Conway BP, Ros WG (2001) Phase I trial of a melanoma vaccine with gp100(280-288) peptide and tetanus helper peptide in adjuvant: immunologic and clinical outcomes. Clin Cancer Res 7: 3012-3024.

Suekane S, Nishitani M, Noguchi M, Komohara Y, Kokubu T, Naitoh M, Honma S, Yamada A, Itoh K, Matsuoka K, Kanayama H (2007) Phase I trial of personalized peptide vaccination for cytokine-refractory metastatic renal cell carcinoma patients. Cancer Sci 98: 1965-1968.

Suzuki N, Maeda Y, Tanaka S, Hida N, Mine T, Yamamoto K, Oka M, Itoh K (2002) Detection of peptide-specific cytotoxic T lymphocyte precursors used for specific immunotherapy of pancreatic cancer. Int $J$ Cancer 98: 45-50.

Uemura H, Fujimoto K, Tanaka M, Yoshikawa M, Hirao Y, Uejima S, Yoshikawa K, Itoh K (2006) A phase I trial of vaccination of CA9-derived peptides for HLA-A24-positive patients with cytokine-refractory metastatic renal cell carcinoma. Clin Cancer Res 12: 1768-1775.

von Mehren M (2005) Colorectal cancer vaccines: what we know and what we don't know. Semin Oncol 32: 76-84.

Walter S, Weinschenk T, Stenzl A, Zdrojowy R, Pluzanska A, Szczylik C, Staehler M, Brugger W, Dietrich PY, Mendrzyk R, Hilf N, Schoor O, Fritsche J, Mahr A, Maurer D, Vass V, Trautwein C, Lewandrowski P, Flohr C, Pohla H, Stanczak JJ, Bronte V, Mandruzzato S, Biedermann T, Pawelec G, Derhovanessian E, Yamagishi H, Miki T, Hongo F, Takaha N, Hirakawa K, Tanaka H, Stevanovic S, Frisch J, Mayer-Mokler A, Kirner A, Rammensee HG, Reinhardt C, Singh-Jasuja H (2012) Multipeptide immune response to cancer vaccine IMA901 after single-dose cyclophosphamide associates with longer patient survival. Nat Med 18: 1254-1261.

cc)(i)(2) (2) This work is licensed under the Creative Commons (c) Attribution-NonCommercial-Share Alike 3.0 Unported License. To view a copy of this license, visit http://creativecommons. org/licenses/by-nc-sa/3.0/ 